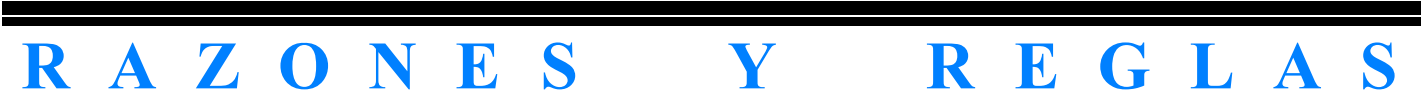




\section{SOBRE LA RACIONALIDAD DE DICTAR Y SEGUIR REGLAS}

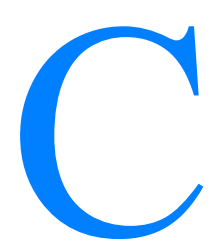

asi veinte años después de la publicación de Practical Reason and Norms, de Joseph Raz, creo que se encuentra ya bastante extendida la convicción, vigorosamente defendida en esa obra, de que la teoría del derecho debe tener su punto de partida en la clarificación de las formas de razonamiento práctico que, allí donde existe un sistema jurídico, desarrollan en relación con él tanto sus operadores como los ciudadanos a los que se aplica. Es sin duda un lugar común afirmar que todo derecho reclama para sí autoridad legítima y que, por consiguiente, pretende proporcionar a sus destinatarios razones para actuar que no son sólo -ni principalmente- de tipo prudencial. Pero la clarificación del sentido exacto de esas pretensiones exige analizar con precisión la relación entre razones y reglas dictadas por autoridades, esto es, dar cuenta del papel de estas reglas en los razonamientos prácticos tanto desde el punto de vista de sus edictores como desde el de sus destinatarios. Y esa es la cuestión en torno a la cual gira este trabajo.

En rigor, un planteamiento como éste sólo podría desarrollarse sobre bases sólidas si antes se han despejado un buen número de dificultadas previas. En primer lugar habría que aclarar, naturalmente, qué se entiende por «razón para la acción», qué tipos de razones para actuar hay y qué relaciones median entre ellas (cuestiones que, como es notorio, distan mucho de ser pacíficas). Y en segundo lugar habría que argumentar la pertinencia misma del enfoque que se propone, puesto que no faltan quienes cuestionan la idea aquí presupuesta de que la mejor forma de entender la naturaleza de las reglas pasa por su intelección en términos de razones para actuar. Aquí, sin embargo, no voy a abordar ninguna de estas cuestiones (de las que me he ocupado extensamente en otro lugar: Bayón, 1991a). En relación con las primeras, baste con señalar que a mi entender un buen número de problemas formales o estructurales que tienen que ver con cómo se razona adecuadamente a partir de las razones relevantes -como, por ejemplo, el que tiene que ver con el papel de las reglas en el razonamiento práctico- se prestan a ser analizados con independencia de cómo se responda al problema 
sustantivo previo de qué (y en virtud de qué) cuenta en un caso dado como una razón relevante. En cuanto a la segunda dificultad, en vez de intentar construir alguna clase de argumento general en favor del enfoque adoptado prefiero que sean ustedes los que juzguen al término de la exposición si nos ha conducido o no a alguna conclusión interesante.

En la literatura acerca de la naturaleza de las reglas desde el punto de vista de su papel en los razonamientos prácticos hay a mi entender dos hitos fundamentales. El primero es, naturalmente, la ya mencionada obra de Raz, en la que el concepto clave es el de razón excluyente. Esa noción, sin embargo, ha sido objeto de reiteradas y a mi juicio insuperables críticas, que no pretendo en modo alguno reproducir aquí en detalle ${ }^{1}$ (aunque sí aludiré brevemente a las discusiones en torno a dicho concepto sólo para entresacar unas pocas ideas de las que intentaré servirme más tarde). En cualquier caso -y creo que esto merece ser destacado-, el fracaso de esa noción nos coloca en una situación incómoda, puesto que si no me equivoco la forma más común de entender las relaciones de autoridad y la especificidad estructural del razonamiento jurídico parece descansar precisamente sobre esa idea ahora puesta en tela de juicio. Necesitamos, por tanto, reconstruir sobre bases nuevas nuestra comprensión de estas cuestiones.

Esas bases, me parece, bien podrían ser las que nos proporciona F. Schauer en Playing by the Rules, el segundo de esos hitos fundamentales a los que me refería hace un momento. En mi opinión Schauer ha puesto a punto un valioso aparato conceptual, que arroja luz nueva sobre algunos temas clásicos de la teoría del derecho y del que voy a servirme aquí en gran medida. Si bien, a mi juicio, Schauer está más cerca del blanco de lo que pueda estar cualquier otro que haya analizado con anterioridad los mismos problemas, intentaré también evaluar críticamente su punto de vista y sugerir algunas correcciones al mismo que me parecen pertinentes.

\section{Razones excluyentes: una explicación fallida del papel de las reglas en el razonamiento práctico}

Puede ser útil exponer abiertamente y desde el principio mi discrepancia con Raz: a mi entender, un agente verdaderamente racional no puede en ningún caso aceptar reglas como razones excluyentes. Eso es tanto como decir que un agente racional nunca queda eximido de componer el balance de todas las razones en juego y de actuar con arreglo al resultado del mismo. Por tanto, si un agente aprecia que lo debido, todas las cosas consideradas, no coincide con lo exigido por una regla y no obstante decide seguirla, su decisión

${ }^{1}$ Vid. Clarke, 1977; Flathman, 1980, 111-113 y 258-259; Gans, 1981, cap. IV; Gans, 1986; Moore, 1989; Perry, 1989; Regan, 1989; Alexander, 1990; Bayón, 1991a, apartado 8.2; Bayón 1991b; Hurd, 1991; Shiner, 1992; Edmundson, 1993. 
sólo puede ser calificada como el producto de una irracional reverencia hacia la regla.

Creo que Raz admitiría la tesis que acabo de sostener si la deliberación práctica se desarrollara siempre en condiciones ideales, en las que el agente maneja información perfecta, dispone de un tiempo ilimitado para deliberar y no se ve envuelto en problemas de acción colectiva. Pero naturalmente la realidad no es así. Y lo que Raz nos sugiere es que el papel distintivo de las reglas en la deliberación práctica de un agente racional consiste en operar como mecanismos de toma de decisiones ciertamente subóptimos en relación con condiciones de deliberación ideales, pero posiblemente óptimos en circunstancias de deliberación reales. Porque en las circunstancias del mundo real el intento de actuar en cada caso con arreglo al balance de razones de primer orden (es decir, lo que yo he afirmado que debe hacer siempre un agente racional) podría resultar autofrustrante, en el sentido de que podría haber un procedimiento indirecto y alternativo de toma de decisiones que en conjunto -aunque no necesariamente en cada caso nos aproximara más a las decisiones correctas con arreglo a aquel balance. Y en esas circunstancias la racionalidad exigiría precisamente seguir ese procedimiento indirecto.

Las razones excluyentes serían entonces estrategias indirectas que, en circunstancias no ideales, servirían para maximizar en conjunto la conformidad con las razones de primer orden que excluyen ${ }^{2}$; y una razón excluyente sería válida, es decir, el agente tendría realmente una razón de esa clase, cuando sea cierto que la mejor estrategia de la que dispone en unas circunstancias dadas para actuar de acuerdo con las razones relevantes consiste no en intentar determinar por sí mismo qué resulta de su balance, sino en postergar su propio juicio al respecto y tomar la razón excluyente como guía de su acción ${ }^{3}$.

${ }^{2}$ A lo largo de la obra de Raz no siempre se ha manejado el concepto de razón excluyente en este sentido, que es a mi juicio, sin embargo, el dotado de mayor coherencia y que en principio podría resultar más defendible. Sobre ello, vid. Bayón, 1991b, 43-50.

${ }^{3}$ Por todo ello, no debe sorprendernos que, como ha señalado Eerik Lagerspetz (Lagerspetz, 1989, 65-67), un precedente directo de las tesis de Raz se encuentre no tanto en el remoto lugar en que lo localizó Hart -el concepto hobbesiano de mandato- (Hart, 1982, 244), sino en la obra mucho más próxima en el tiempo (pero probablemente más alejada de la atención de los teóricos del derecho) de un economista estudioso de la elección racional en condiciones no ideales. Se trata de Herbert Simon, que no en vano ha encontrado un lugar en el pensamiento económico contemporáneo como teórico de la racionalidad limitada y que, exactamente como Raz, sostiene que la postergación del juicio propio es el elemento clave para entender lo que significa aceptar las reglas dictadas por una autoridad. Más aún, según Simon los supuestos en los que dicha actitud no sólo no es irracional, sino, antes bien, lo que exige la racionalidad rectamente entendida, son justamente aquellos dos a los que también alude Raz: bien cuando la autoridad es respecto a la decisión a tomar más experta que el sujeto que delibera, bien cuando se trata de resolver problemas de coordinación (Simon, 1959, 125-139). 
A partir de ahí, resulta fácil entender cuándo una regla constituye para Raz una razón excluyente válida: cuando es cierto -y no siempre lo es- que en conjunto el agente maximiza la conformidad con las razones para actuar aplicables al caso si se limita a seguir la regla (incluso si él considera en un caso dado que lo debido, todas las cosas consideradas, no coincide con lo exigido por la regla). Y las relaciones de autoridad se definirían así: pretende autoridad legítima quien sostiene -sincera o insinceramente- que las reglas que emite constituyen para sus destinatarios razones excluyentes válidas; y acepta una autoridad como legítima quien da por buena esa pretensión. Y por consiguiente, recto sensu, no acepta una autoridad (ni sus reglas) quien en cada caso en que una regla es aplicable intenta determinar el resultado del balance de razones relevantes y hace lo que la regla exige si y sólo si coincide con ese resultado; ni reclama para sí autoridad quien dicta reglas para que sus destinatarios deliberen y actúen de ese modo ante ellas.

Hasta aquí, prescindiendo de muchas cosas que ahora no vienen al caso, la posición de Raz. Lo que interesa destacar es que para Raz no tiene por qué ser irracional-aunque a veces sí lo sea- aceptar y seguir las reglas dictadas por una autoridad como razones excluyentes. Entonces, la cuestión interesante es ésta: ¿es correcto sostener lo contrario, como yo he hecho al comienzo, incluso cuando se reconoce que la deliberación práctica real se desarrolla típicamente en condiciones no ideales? En mi opinión sí lo es. Pero para entender por qué lo es hay que superar una idea inaceptablemente simple de lo que significa determinar qué es lo debido, todas las cosas consideradas. No toma en cuenta todas las cosas relevantes quien considera que el paisaje de las razones para actuar no se puede ver afectado en modo alguno por la existencia de reglas e instituciones sociales; ni tampoco quien se muestra insensible ante la importancia de sus propias deficiencias epistémicas y ante el coste de adquirir y procesar información. La consideración de estos factores obliga, según creo, a refinar la teoría de las razones para actuar dando entrada a dos ideas.

La primera es la que, siguiendo a Gans, podemos llamar razones invocadas por las reglas (Gans, 1981, cap. VIII). Un agente puede tener dos clases de razones para realizar una acción exigida por una regla dictada por una autoridad. Unas (dependientes del contenido) las tendría de igual modo si la regla no hubiera sido dictada. Otras, sin embargo, las tiene precisamente porque se ha dictado y no tienen que ver con la calidad intrínseca del acto exigido (son independientes del contenido). Estas razones, cuando existen, no han sido en sentido estricto «creadas por la regla»: lo que sucede, más bien, es que la alteración del contexto fáctico (fundamentalmente, la alteración de las expectativas y disposiciones de conducta de los agentes implicados) de la que ha podido ser causa la emisión de la regla ha atraído hacia la acción exigida razones preexistentes que hasta entonces no eran específicamente razones para esa acción. Aquí no puedo explorar esta idea en toda su complejidad. Pero, en cualquier caso, lo que me interesa resaltar es que 
un agente que trata de determinar si, todas las cosas consideradas, debe o no realizar la acción exigida por una regla debe naturalmente incluir en el balance todas las razones relevantes: también, si las hay, las invocadas por las reglas.

La segunda idea que ha de ser introducida es la que Regan ha denominado reglas indicativas (Regan, 1989, 1.004-1.013), que a mi juicio aclara satisfactoriamente el papel en el razonamiento práctico de lo que, con contornos no muy claros, suele denominarse reglas de experiencia [rules of thumb]. Las reglas indicativas son mecanismos para minimizar errores en condiciones de incertidumbre y ahorrar costes de decisión. Consisten en generalizaciones acerca de lo que suele ser correcto en ciertas clases de situaciones: no son por tanto, en sentido estricto, razones para actuar, sino razones para creer en situaciones de incertidumbre que cierta acción es con la mayor probabilidad la que uno tiene razones para realizar. Como tales, son naturalmente falibles. Pero cuando el agente sabe que no sabe lo que resulta del balance de razones, la racionalidad práctica le exige adoptar aquel procedimiento de decisión que, aun falible, cuente con las mayores probabilidades de aproximarle a la decisión correcta (y que es por lo tanto, en esas circunstancias, el más fiable). Las reglas indicativas, por tanto, no son en modo alguno razones para postergar el juicio propio acerca de los méritos del caso, sino mecanismos para conjeturar cuáles son éstos con mayor probabilidad cuando dicho juicio no puede ser formado.

Ahora podemos decir que el agente verdaderamente racional que trata de determinar seriamente el resultado del balance de razones, esto es, de identificar lo debido, todas las cosas consideradas, toma también en cuenta -si las hay- las razones invocadas por las reglas y -si es necesario- las reglas indicativas que puedan ser aplicables al caso; y que al hacerlo desarrolla lo que, estipulativamente, llamaré un balance de razones refinado o «esclarecido». No obstante, con ello no llega aún a aceptar ninguna regla como razón excluyente. Sigue entendiendo que si lo debido, todas las cosas consideradas (pero con arreglo a un balance esclarecido), no coincide con lo exigido por una regla, siempre será irracional seguir la regla. Lo interesante ahora es entender qué clase de argumento necesita Raz para resistirse a esa conclusión. Necesita probar que alguna $v e z$ es cierto que en conjunto el agente maximiza la conformidad con las razones para actuar aplicables al caso si se limita a seguir la regla (incluso aunque él considere en un caso dado que lo debido, todas las cosas consideradas -en un balance esclarecido-, no coincide con lo exigido por la regla). Si no hay ninguna situación de este tipo, entonces la clase de las razones excluyentes que son válidas es vacía. Y si lo es, el concepto mismo de razón excluyente resulta superfluo.

La carga de la prueba, por tanto, cae sobre Raz. Como es sabido, Raz ha sostenido que hay al menos dos contextos en los que la racionalidad práctica exigiría aceptar las reglas dictadas por una autoridad como razones excluyentes ${ }^{4}$. Pero me parece que en ninguno de estos dos casos su argumento

${ }^{4}$ Vid. Raz 1975, 64; Raz, 1986, 30, 49-50, 56, 67-69; Raz, 1989, 1194-1196; Raz, 1990, 195. 
tiene éxito. El primero de estos contextos es el de la resolución de problemas de coordinación. Una regla dictada por una autoridad puede proporcionar la solución de un problema de coordinación cuando es causalmente eficaz para modificar el entramado de expectativas de los agentes implicados, lo que se conseguirá cuando todos ellos perciban como solución sobresaliente [salient] la acción conforme a la regla ${ }^{5}$. Si tras la emisión de la regla cada agente tiene razones para creer que lo que los demás harán es lo que ésta exige, entonces es sin duda su propio juicio acerca de lo que, todas las cosas consideradas, resulta del balance de razones relevantes el que le dice que ha de realizar la acción conforme a la regla. Y si, por el contrario, tiene razones para creer que la emisión de la regla no ha sido causalmente eficaz para generar las expectativas requeridas, entonces simplemente no tiene ninguna razón para hacer lo que la regla exige, ni para limitarse a obedecerla postergando su juicio de que no tiene ninguna razón para hacerlo. El argumento de la coordinación, por tanto, no demuestra que hayamos de reconocer razones excluyentes válidas.

Tampoco lo demuestra, en mi opinión, el segundo argumento que propone Raz, centrado en la idea del juicio de un experto. La consideración de este argumento me ofrece por otra parte la ocasión de decir algo más acerca de las reglas indicativas y de cómo, aunque consistan en el fondo en estrategias indirectas para la conformidad con las razones relevantes, difieren profundamente de las reglas aceptadas como razones excluyentes. Un agente trata una regla como «absolutamente transparente» si considera que sólo es racional hacer lo que la regla establece cuando se tiene la certeza de que ésa es la acción correcta según el balance de razones; y como «absolutamente opaca» si considera que ha de hacer siempre lo que la regla establezca aun cuando tenga la certeza de que no es ésa la acción correcta según el balance de razones. Una regla indicativa no es absolutamente transparente, puesto que ofrece una guía racional al agente precisamente cuando éste no sabe con certeza qué resulta del balance de razones; ni absolutamente opaca, puesto que ha de ser simplemente ignorada cuando en un caso dado el agente tiene elementos de juicio para darse cuenta con seguridad de que la acción correcta según el balance de razones no es la que la regla indicativa recomienda.

Volvamos ahora al argumento de Raz. ¿Qué actitud adoptaría un agente racional ante las reglas dictadas por una autoridad si tiene razones para creer que el juicio de ésta acerca de lo que resulta del balance de razones aplicables a cierta de clase de casos suele ser más fiable que el suyo propio? En mi opinión debería aceptar como una regla indicativa que debe cumplir las reglas de esa autoridad, lo que implica, según la explicación propuesta, que no es de ninguna manera racional postergar el propio juicio ante el de aquel

${ }^{5}$ En Bayón, 1991a, 670-673 he intentado explicar con detalle de qué modo puede producirse ese resultado. 
cuyo juicio suele ser más fiable (el «experto») cuando se tiene la certeza de que en una ocasión determinada no lo es, de que en esa ocasión se ha equivocado. Pero es justamente eso lo que exigiría aceptar las reglas de la autoridad como razones excluyentes ${ }^{6}$. Y ello demuestra la significativa distancia que existe entre admitir el papel de las reglas indicativas en la deliberación de un agente racional y aceptar la existencia de razones excluyentes válidas.

Entiendo por tanto que no hay argumentos para dejar de mantener la tesis que presenté al comienzo: que un agente racional nunca puede aceptar reglas como razones excluyentes. Lo que ocurre es que esta tesis tiene implicaciones muy graves. Si aceptar una autoridad es aceptar sus reglas como razones excluyentes (y si pretender autoridad es pretender que las reglas que se dictan sean aceptadas de ese modo por sus destinatarios), entonces la práctica de la autoridad simplemente no puede tener lugar entre sujetos racionales. Chocamos por consiguiente con este dilema: o bien reformulamos el concepto de autoridad, de un modo tal que no haya de resultar por principio incompatible con la racionalidad; o, de lo contrario, tendríamos que admitir que, puesto que en la realidad existen relaciones de autoridad, éstas sólo serían posibles sobre la base de un importante error colectivo (en los términos de Mackie -Mackie, 1977, 35-, deberíamos postular una teoría del error respecto a la práctica real de la autoridad).

No es posible entender el derecho sin relaciones de autoridad. Y uno y otras ocupan un lugar demasiado importante en la vida de las sociedades humanas como para resignarse de entrada a aceptar la segunda de las opciones descritas. En un trabajo anterior (Bayón, 1991a, 689-691) insinué, muy de pasada, una posibilidad alternativa de entender, desde el punto de vista de quien dicta las reglas, qué podría significar pretender autoridad legítima: pretender que lo prescrito por la regla es, tras la emisión de la misma y una vez tomado en cuenta el impacto que dicha emisión haya podido tener sobre la razones para actuar de sus destinatarios, lo que éstos deben hacer, todas las cosas consideradas, cada vez que la regla es aplicable. Ahora entiendo, sin embargo, que esta explicación no es satisfactoria porque ignora algo bastante obvio en cuanto a la forma en que se guía la conducta mediante reglas generales y abstractas. Como creo que la idea a la que me refiero puede entenderse mejor a través del aparato conceptual propuesto por Schauer, permítanme que deje aquí momentáneamente la argumentación para recordar algunas de las ideas centrales de Playing by the Rules.

\section{Un nuevo punto de partida: los modelos de toma de decisiones de Schauer}

La reflexión de Schauer arranca de la constatación de que las reglas dictadas por una autoridad típicamente incluyen demasiado o demasiado poco

${ }^{6}$ El desarrollo completo del argumento resulta más complejo: vid. Bayón, 1991b, 59-61. 
en relación al propósito que guía su producción (de manera que serían, nos dice Schauer, «supraincluyentes» [over-inclusive] y/o «infraincluyentes» [under-inclusive]: Schauer, 1991, 32-33). El sentido de esta críptica afirmación puede aclararse trayendo a la memoria algunas cosas que todos sabemos. En primer lugar, las reglas (entendiendo siempre por tales reglas de mandato generales y abstractas) prescriben cierta clase de conductas a clases de individuos en clases de situaciones. Y hay innumerables formas de agrupar en clases los objetos particulares, dependiendo de cuáles, entre las múltiples propiedades predicables de cada uno de ellos, seleccionemos como relevantes. Ello implica, naturalmente, que objetos encuadrables en una misma clase -por tener todos ellos las propiedades seleccionadas como relevantes- pueden diferir entre sí en incontables aspectos (los considerados irrelevantes para la pertenencia a la clase en cuestión).

En segundo lugar, las reglas tienen una justificación o propósito [rationale]. Se dictan por una razón, para conseguir algún objetivo. Idealmente, existirá un cierto conjunto de acciones (por parte de un conjunto de individuos y en un conjunto de situaciones) tal que su realización (u omisión) implique la satisfacción perfecta de ese objetivo. Llamemos a ese conjunto el conjunto ideal. El problema de quien dicta la regla consiste entonces en cómo comunicar cuál es el conjunto ideal, el conjunto de acciones (por qué conjunto de individuos y en qué conjunto de situaciones) que quiere ver realizadas. Podría referirse a las mismas meramente como aquellas que satisfagan el propósito buscado, pero entonces su identificación en concreto quedaría librada enteramente al juicio de quienes apliquen la directiva. Así que, si desea evitar esa pérdida de control -al menos en la medida de lo posible-, tiene que buscar la forma de agrupar a los miembros del conjunto ideal en una clase, cuya extensión sea lo más parecida posible a la del conjunto ideal, y para pertenecer a la cual haya de concurrir alguna propiedad cuya identificación no dependa del juicio de otro acerca de si queda o no satisfecho el propósito buscado.

Pero, como ya sabemos, cada uno de los miembros del conjunto ideal posee innumerables propiedades, que, una por una, pueden ser predicables también de acciones, individuos y situaciones que no pertenecen al mismo. Más aún, es posible que la única propiedad común a todos los miembros del conjunto ideal sea precisamente satisfacer el propósito de la regla. Así que, nos dice Schauer, todo lo que puede hacer quien dicta la regla es basar la selección en una relación de probabilidad (Schauer, 1991, 29): ha de seleccionar aquellas propiedades cuya concurrencia maximice la probabilidad de que nos hallamos ante miembros del conjunto ideal. Pero ello implica, por supuesto, que frente a una regla formulada con ese criterio podemos encontrar casos en los que la regla es aplicable pero en los que su cumplimiento no promueve su propósito; y casos en los que hacer lo que la regla exige promovería su propósito, pero en los que sin embargo no resulta aplicable. 
Con respecto a los primeros, la regla es supraincluyente; con respecto a los segundos, infraincluyente.

Schauer denomina «experiencias recalcitrantes» a estos tipos de casos en los que no hay un ajuste perfecto entre aplicabilidad de la regla y promoción de su justificación o propósito (Schauer, 1991, 39). Y la aparición de experiencias recalcitrantes proporciona la ocasión para distinguir entre dos modelos básicos de toma de decisiones, cada uno de los cuales asigna un papel diferente a las reglas en el razonamiento práctico ${ }^{7}$.

El primero de esos modelos es el que Schauer denomina «particularista». En él es siempre la justificación subyacente a la regla la que guía la decisión. A la regla, tal y como ha sido formulada, no se le reconoce ningún peso propio o independiente, se considera que no aporta por sí misma nada al proceso de toma de decisión, es vista, simplemente, como una ejemplificación ilustrativa y siempre derrotable [defeasible] de su justificación, es decir, como algo completamente transparente con respecto a las razones que están tras ella. Son éstas las que guían realmente la decisión en cada caso concreto y cada vez que la regla resulta supraincluyente o infraincluyente simplemente se deja a un lado y se resuelve directamente en virtud de la justificación subyacente.

El segundo modelo es el que cabría llamar con propiedad «basado en reglas» (el único, podría decirse, que trata a las reglas como auténticas reglas). Con arreglo al mismo, la regla es la que guía la decisión en cada caso concreto en que resulta aplicable, incluso cuando su aplicación no sirve a la promoción de su propósito u objetivo, es decir, incluso cuando lo que la regla exige no coincide en un caso concreto con lo que exigiría su justificación subyacente. Es la regla la que controla la decisión, bloqueando, incluso en el caso de experiencias recalcitrantes, el recurso directo a las razones que están tras ella. Como dice Schauer, la regla no es maleable a la luz de su justificación, sino que se torna resistente o queda resguardada [entrenched] frente a ella (Schauer, 1991, 42).

Comparando estos conceptos con las categorías de Raz, creo que puede afirmarse que en el modelo basado en reglas las directivas que ha dictado una autoridad son aceptadas como razones excluyentes. Sería un error, sin embargo, pensar que adoptar el modelo particularista frente a un conjunto de directivas dictadas por una autoridad equivale sin más a actuar según el resultado del balance de todas las razones relevantes, es decir, a hacer lo debido, todas las cosas consideradas $^{8}$. Quien sigue el modelo particularista frente a un conjunto de reglas sólo maneja como razones relevantes las justificaciones subyacentes a las reglas dictadas: es decir, acepta ya que éstas

\footnotetext{
${ }^{7}$ Vid. Schauer, 1991, 51-52, 54, 76-77, 84-85.

${ }^{8}$ Un error que, en alguna medida, propicia el mismo Schauer cuando afirma que «[el] procedimiento que denomino "particularista" está bastante próximo a la idea de Joseph Raz de actuar "según el balance de razones"» (Schauer, 1991, 77, nota 1).
} 
han delimitado el ámbito de las razones relevantes y lo que propugna es una determinada tesis acerca de cómo debe desarrollarse el razonamiento práctico dentro de ese ámbito. Por supuesto la identificación de las «justificaciones subyacentes a las reglas dictadas» constituye en sí misma un serio problema. Pero para no romper el orden de la argumentación prefiero dejar por el momento al margen esa cuestión.

El siguiente paso de importancia en la argumentación de Schauer es la introducción de un tercer modelo, que puede ser considerado como una variante refinada del particularista y al que denomina «particularismo sensible a las reglas» (Schauer, 1991, 93-100). En él, no sólo se presta atención a las justificaciones subyacentes a las reglas, sino también a las justificaciones para presentar esas justificaciones en forma de reglas. Recuérdese que una de las posibilidades de quien dicta la regla a la hora de comunicar cuál es el conjunto ideal que quiere ver realizado consistía simplemente en prescribir la realización de las acciones que promovieran el propósito buscado. Lo que ocurre es que seguramente hay en muchos casos buenas razones para no utilizar esa posibilidad, es decir, para dictar reglas potencialmente supra- e infraincluyentes (favorecer la certeza y la previsibilidad, preservar un cierto esquema de legitimidad relativo al papel que corresponde en la toma de decisiones a cada una de las instituciones que componen un aparato de autoridad, etc.). En el particularismo sensible a las reglas, quien toma la decisión sobre el caso concreto añade a las razones subyacentes a las reglas las razones para tener esas reglas, componiendo con ambas un balance más sofisticado que en el modelo particularista puro. La diferencia entre éste y el particularismo sensible a las reglas corre en paralelo a la que presenté en un momento anterior entre una deliberación tosca o simplista según el balance de todas las razones relevantes y otra refinada o esclarecida. Pero, en cualquier caso, lo que interesa destacar es que existe aún una genuina diferencia extensional entre el particularismo sensible a las reglas y el modelo basado en reglas: aunque en el primero se reconoce la importancia de tomar en cuenta el valor de disponer de reglas, sigue siendo el balance de las justificaciones subyacentes a las reglas y de las justificaciones para tener esas reglas, y no las reglas mismas, el que guía las decisiones.

Schauer cree que aún puede diferenciarse un cuarto modelo, precisamente aquélque goza de sus mayores simpatías. Pero por el momento no voy a referirme a él. Diré tan sólo que, si bien me parece obvio que entre los tres modelos ya descritos existe una genuina diferencia extensional, sospecho que ésta no es tan clara entre el particularismo sensible a las reglas y ese cuarto modelo que aún no he presentado.

Lo que ahora me parece importante mencionar son las observaciones de Schauer acerca de qué es lo que hace posible la diferencia extensional entre el modelo particularista y el modelo basado en reglas. La idea clave es aquí la de autonomía semántica (Schauer, 1991, 55 ss.). Para que la regla pueda ofrecer una guía para la decisión que no sea coextensa con la que proporciona 
su justificación subyacente -es decir, para que la regla pueda funcionar auténticamente como regla en sentido estricto-, el significado de los términos en que se ha formulado debe poder ser determinado con total independencia del juicio acerca de lo que exigiría esa justificación. Cuando, por el contrario, la formulación de la regla incluye términos con carga valorativa, la resistencia o puesta a resguardo [entrenchment] de la regla frente a su justificación subyacente es imposible: la única forma de determinar qué casos gobierna la regla consiste precisamente en determinar cuándo queda satisfecho y cuándo no el objetivo o propósito buscado.

Diremos por tanto que el modelo de toma de decisiones basada en reglas sólo es posible con directivas que posean autonomía semántica. Y, sin necesidad de entrar en este momento en los problemas de una teoría de la individualización de normas dentro de un sistema normativo, habría que añadir ahora: sólo es posible con directivas que posean autonomía semántica y que no sean excepcionadas por otras que pertenezcan también al sistema y que carezcan de ese rasgo. Esta, me parece, es una condición necesaria para que pueda desarrollarse la toma de decisiones basada en reglas entendida en sentido estricto.

No es, sin embargo, una condición suficiente y el haberlo hecho notar me parece un mérito destacable del análisis de Schauer. El papel que juegan las reglas en un proceso de toma de decisiones depende finalmente de la actitud ante ellas que adopte aquel a quien compete decidir. Las características estructurales de la regla -que posea o no autonomía semántica; que sea o no excepcionada por otras que carecen de ese rasgo- determinan cómo puede operar en el razonamiento práctico, no cómo opera. Es perfectamente posible desarrollar razonamientos prácticos que sigan la pauta del modelo particularista en relación con un conjunto de reglas que, por sus características estructurales, podrían ser tratadas como genuinas reglas. Por eso, como dice Schauer, es «algo a propósito de la regla y no la regla misma» (Schauer, 1991, 128) lo que determina de qué modo opera finalmente en el razonamiento práctico. Estas observaciones, como trataré de mostrar más adelante, son del máximo interés a la hora de replantear algunos temas clásicos de la teoría del derecho como la distinción entre reglas y principios o los conceptos de caso claro y caso difícil.

Hasta aquí, reducido al mínimo necesario, el análisis conceptual. Pero el poner a punto estas herramientas teóricas tiene un mero valor instrumental como paso previo para dos tipos de investigación que son las que realmente nos interesan: la primera, de carácter empírico, consiste en preguntarse cuál de estos modelos describe de manera más fiel la práctica del razonamiento jurídico tal y como se desarrolla realmente en relación con un sistema jurídico determinado; la segunda, de carácter normativo o justificatorio, consiste en preguntarse con arreglo a cuál de ellos debería desarrollarse (o, si se quiere, cuál es más defendible en términos de racionalidad). Comenzaré por esta última cuestión, que nos permite volver sobre el problema 
que quedó pendiente acerca de los términos en que podría concebirse una relación de autoridad entre agentes racionales.

\section{Reformulación del concepto de autoridad: emisión y seguimiento de reglas sin razones excluyentes}

Creo que ahora puede entenderse con facilidad por qué, en contra de lo que pensé en algún momento, no es fácil mantener la idea de que pretender autoridad legítima es pretender que lo prescrito por la regla es, tras la emisión de la misma y una vez tomado en cuenta el impacto que dicha emisión haya podido tener sobre las razones para actuar de sus destinatarios, lo que éstos deben hacer, todas las cosas consideradas, en todos los casos en los que la regla es aplicable. Esta tesis simplemente ignora el carácter supra- e infraincluyente de cualquier regla con autonomía semántica. La autoridad que dicta una regla con autonomía semántica sabe que no puede mantener que lo prescrito por ella es siempre -i. e., en todos los casos en los que la regla resulta aplicable- lo que con arreglo a la justificación subyacente resultaría debido, todas las cosas consideradas. Si tampoco puede sostener que las reglas que dicta constituyen para sus destinatarios razones excluyentes válidas, ¿en qué puede consistir entonces su pretensión para que sea racionalmente sostenible?

Una forma de buscar la salida del atolladero puede consistir en preguntarse si no podrá haber alguna clase de razón para que una autoridad dicte e imponga una regla como regla en sentido estricto aun sabiendo que lo que ella prescribe no siempre será lo debido con arreglo a su propósito o justificación subyacente. Es muy posible que el modo usual de responder a esta pregunta -y de responder con una negativa- esté condicionado por lo que podríamos llamar la tesis de la simetría, en virtud de la cual para quien dicta la regla sólo puede ser racional exigir aquello que para su destinatario sea racional aceptar: si un agente racional no puede aceptar reglas como «reglas genuinas» -esto es, no puede seguir el modelo de toma de decisiones basada en reglas-, entonces un legislador racional no podría tampoco pretender que las reglas que dicta se tomen como tales ${ }^{9}$.

Uno de los puntos más sobresalientes del análisis de Schauer consiste precisamente en desafiar esta tesis de la simetría (Schauer, 1991, 128-134). Schauer admite que un agente racional no puede aceptar ninguna regla como regla en sentido estricto (ibid., 129), lo que significa que, incluso si coincide en considerar como razones relevantes precisamente todas las justificaciones de las reglas -y para tener esas reglas- dictadas por la autoridad

${ }^{9}$ Nowell-Smith, por ejemplo, está propugnando esta tesis de la simetría cuando escribe que la autoridad «es una calle de dos direcciones», en el sentido de que «en un mundo en el que los destinatarios rara vez o nunca considerasen que las directivas proporcionan razones excluyentes [...], ningún hombre racional se dirigiría a otro en forma imperativa con la intención de que el destinatario tomara lo que se le dice como una orden» (Nowell-Smith, 1978, 43). 
y solamente ellas, su razonamiento práctico no podrá desarrollarse ni aun en ese caso según la pauta del «modelo basado en reglas». Para el agente la opción más racional parece el modelo particularista sensible a las reglas, lo que implica que, en cada caso en que la regla es aplicable, habrá de determinar si debe o no ser seguida.

Ahora bien, desde el punto de vista de quien dicta la regla, el destinatario puede cometer dos tipos de errores al desarrollar ese juicio: puede concluir que no debe seguir la regla cuando con arreglo a las justificaciones subyacentes sí debería hacerlo (no seguimiento injustificado) o que debe seguir la regla cuando no debería hacerlo (seguimiento injustificado). Y si el legislador tiene razones para creer que el número e importancia de los casos de no seguimiento injustificado será mayor que el de los casos de seguimiento injustificado, entonces podría tener razones para imponer sus reglas como reglas en sentido estricto aun cuando admita que no es racional para sus destinatarios seguirlas como tales. El argumento que respalda esta conclusión merece ser expuesto con algún detenimiento.

Si la autoridad sanciona todas las transgresiones de la regla, incluso en aquellos casos en los que ex post la propia autoridad admitiría que la transgresión estaba justificada con arreglo a las justificaciones subyacentes, y si las sanciones tienen la suficiente fuerza como para condicionar de un modo efectivo la conducta de los destinatarios, entonces se conseguirá, en términos generales, que éstos actúen como si aceptaran las reglas como reglas en sentido estricto, algo que se admite abiertamente que sería irracional que hicieran. Y el resultado de esta estrategia sería un conjunto de decisiones que no coincidiría con el que resultaría de seguir perfectamente el modelo particularista sensible a las reglas, pero que, según la hipótesis que se maneja, globalmente se aproximaría más a ese objetivo que el conjunto de decisiones que adoptarían los destinatarios de las reglas al tratar de seguir por su cuenta -y seguir imperfectamente- ese mismo modelo. Pretender autoridad legítima sería entonces sostener que imponiendo las reglas dictadas como reglas en sentido estricto se llega precisamente a dicho resultado (lo que sería perfectamente compatible con reconocer que lo prescrito por esas reglas no es siempre lo que con arreglo a su justificación subyacente resultaría debido, todas las cosas consideradas; $y$ con reconocer que las reglas que se dictan no constituyen para sus destinatarios razones excluyentes válidas, porque no existe tal cosa).

Todo el argumento, como se ve, está encaminado a demostrar que, si bien un agente racional siempre ha de hacer lo debido, todas las cosas consideradas, y por consiguiente no puede adoptar el modelo de toma de decisiones basadas en reglas frente a las normas dictadas por una autoridad, un legislador racional sí puede justificadamente (en determinadas condiciones) dictar sólo reglas que por sus características estructurales pueden operar como reglas en sentido estricto y manipular estratégicamente las razones prudenciales de sus destinatarios para que éstos, aunque racionalmente deben 
desarrollar frente a aquellas reglas razonamientos prácticos que no siguen la pauta del modelo basado en reglas, acaben actuando como si lo hubieran hecho (y hubieran obrado en consecuencia). Lo que el argumento sostiene es que, sin paradoja alguna, eso puede ser precisamente lo que como legislador debe hacer, todas las cosas consideradas. Por comodidad, me referiré simplificadamente a esta idea diciendo que el argumento está dirigido a demostrar la justificación racional que puede tener un legislador para implantar un modelo puro de toma de decisiones basada en reglas.

Ahora bien, el argumento choca con una seria dificultad: su lógica interna exige defender la idea de que puede haber una sanción justificada por la violación justificada de una regla, algo que a mí me parece difícil de aceptar ${ }^{10}$. Si la autoridad reconoce que las reglas que dicta son supra- e infraincluyentes con respecto a las que ella misma considera sus justificaciones subyacentes, entonces habrá actos que violen las reglas y que la propia autoridad reconozca como justificados, todas las cosas consideradas. Y lo que el argumento demanda es que se reconozca que hay una justificación racional para sancionar también esta clase de actos. El problema no es, como parece creer Schauer (Schauer, 1991, 133), que en la práctica la implantación de un modelo semejante pueda resultar difícil porque muchos de los llamados a administrar las sanciones podrían tener reparos para sancionar los actos de esa clase: el problema es más bien que esos reparos parecen perfectamente justificados. A la vista de lo que exige para una autoridad implantar un modelo puro de toma de decisiones basada en reglas, me parece difícil aceptar que pueda haber una justificación para ello ${ }^{11}$.

Alternativamente, como señala Schauer (ibid.), la autoridad podría optar por sancionar -aunque quizá con especial severidad- sólo las transgresiones de las reglas que ex post se consideraran no justificadas a la luz de las justificaciones subyacentes. A pesar de ello, dice Schauer, también de ese modo se está ya manipulando estratégicamente el razonamiento práctico del destinatario de las reglas. Porque éste no tiene ex ante una certidumbre plena acerca de qué transgresiones de la regla considerará ex post justificadas quien administra las sanciones: y sabiendo que el seguimiento injustificado no trae consigo ninguna sanción y el no seguimiento injustificado sí, en caso de duda lo más seguro es cumplir la regla. Y quizá esto sea todo lo que se necesita para conseguir el objetivo buscado (un procedimiento indirecto que en conjunto -y bajo las condiciones que se han presupuesto- nos aproxime más a los resultados correctos), sin tropezar con el

\footnotetext{
${ }^{10}$ Sobre ello, vid. Hurd, 1993; y Alexander y Sherwin, 1994, 1200, nota 18.
}

${ }^{11}$ Postema ha señalado otra objeción: que lo que cuenta al valorar un procedimiento de decisión no es sólo si conduce en conjunto a las mejores decisiones, sino también de qué modo consigue hacerlo; y que la implantación del modelo propuesto no lo hace del modo correcto, puesto que corrompe las decisiones de los destinatarios de las normas, que dejan de hacer sólo por temor lo que perciben que tienen una justificación para hacer. Vid. Postema, $1991,819$. 
problema que supone tener que defender como justificada la sanción de actos que se consideran justificados. Pero nótese que, en ese caso, la autoridad simplemente ha renunciado a implantar un modelo puro de toma de decisiones basada en reglas, ha abandonado la pretensión de que sus reglas sean tomadas como reglas genuinas.

En suma, en contra de la idea -en la que Schauer basa la tesis de la asimetría de la autoridad- de que las razones para imponer reglas constituyen una cuestión distinta de la de las razones para seguirlas, yo diría que las razones para seguirlas (o para no seguirlas) sí que afectan a las razones para tratar de imponerlas como reglas genuinas. Y, por todo ello, me parece que no sólo es irracional para un agente adoptar el modelo de toma de decisiones basada en reglas frente a las reglas dictadas por una autoridad, sino que también sería normativamente indefendible el intento de un legislador de implantarlo. Quizá, después de todo, no se pueda prescindir tan fácilmente de la idea de que para quien dicta la regla sólo puede ser racional exigir aquello que para su destinatario sea racional aceptar.

\section{Principios y reglas, positivismo presuntivo y fronteras del razonamiento jurídico}

Si todo la anterior es correcto, me parece que sería muy difícil mantener que la práctica del razonamiento jurídico, tal y como la desarrollan los órganos jurisdiccionales, debería seguir la pauta del modelo puro de toma de decisiones basada en reglas. Pero es que, además, de hecho no lo hace. Se trata por tanto de un modelo no sólo injustificable como ideal, sino también descriptivamente inadecuado. Es descriptivamente inadecuado, en primer lugar, porque ningún sistema jurídico conocido posee las características que son condición necesaria para adoptar ante las normas que lo componen el modelo basado en reglas: no están compuestos sólo por reglas que posean autonomía semántica y en ellos no está excluido el que las reglas que sí posean ese rasgo sean excepcionadas por otras que carecen de él. Por supuesto, sólo con esto ya basta para que el modelo sea descriptivamente inadecuado. Pero aún hay más. Como se explicó anteriormente, que las reglas que por sus características estructurales pueden operar en el razonamiento práctico como reglas genuinas operen realmente como tales depende de la actitud que adopten ante ellas los órganos aplicadores. Por eso, incluso si un sistema jurídico -o quizá una parte de él- cumpliera aquellas condiciones necesarias, el modelo basado en reglas seguiría siendo descriptivamente inadecuado a menos que de hecho tuviera lugar la práctica de aceptar sus reglas como reglas genuinas.

Esta última idea puede servir, a mi juicio, para proyectar algo de luz sobre algunos temas clásicos de la teoría del derecho. Uno de ellos es la distinción entre principios y reglas. Atienza y Ruiz Manero han defendido recientemente la tesis de que principios y reglas difieren entre sí en una doble dimensión: estructuralmente, en las reglas la condición de aplicación estaría 
determinada en forma cerrada, mientras que en los principios estaría determinada en forma abierta; en cuanto al papel en el razonamiento práctico, las reglas operarían como razones perentorias, mientras que los principios operarían como razones no perentorias o de primer orden; y si las reglas pueden operar de ese modo es precisamente porque poseen el rasgo estructural mencionado (Atienza y Ruiz Manero, 1991, 108, 111-112; 1992, 334).

Como ya he señalado, creo que en el plano estructural hay una diferencia importante entre las directivas que podrían operar en el razonamiento práctico como reglas genuinas (las que tienen autonomía semántica) y las que no pueden hacerlo (las que no la tienen). Pero me parecería equívoco decir que las primeras son genuinas reglas, o que operan en el razonamiento práctico como «razones perentorias». Que lo hagan o no dependerá, como ya sabemos, de la actitud -o tipo de práctica interpretativa- que adopte frente a ellas el aplicador. Supongamos, por ejemplo, que adopta la actitud recomendada por Calabresi en A Common Law for the Age of Statutes (Calabresi, 1982), o que sostiene, como en aquella comunidad imaginaria en la que existe una «actitud interpretativa» de la que se sirve Dworkin como ejemplo en Law's Empire, que «las reglas estrictas han de ser entendidas, o aplicadas, o extendidas, o modificadas, o cualificadas, o limitadas» a la luz de las (mejores) justificaciones subyacentes al sistema (Dworkin, 1986, 47): entonces, simplemente, no operan en su razonamiento práctico como reglas genuinas directivas que podrían hacerlo (suponiendo que esto último sea cierto). Creo que Atienza y Ruiz Manero han visto con agudeza que alguna característica estructural es condición necesaria para que una directiva opere en el razonamiento práctico como regla genuina. Pero acaso no han reparado -si les entiendo bien- en que no es condición suficiente. Y quizá es por eso por lo que su opinión acerca de cuál es esa característica estructural no me parece la más feliz, porque no separa con nitidez las cuestiones relativas a cómo es una directiva y las relativas a qué actitud se adopta ante ella: quien adopta ante una directiva el modelo particularista de toma de decisiones puede afirmar con naturalidad que su condición de aplicación es abierta; quien ante esa misma directiva adopta el modelo puro basado en reglas (supuesto que reúna la que a mí me parece auténtica condición necesaria para ello: que posea autonomía semántica), se inclinará con igual naturalidad a decir que es cerrada.

Estas reflexiones deben orientar también nuestra comprensión de la diferencia entre casos claros y casos difíciles. Aquí lo fundamental es distinguir los problemas que tienen que ver con el significado de los términos en que está formulada una directiva de aquellos otros que tienen que ver con la adopción, en relación con ella, de uno u otro modelo de toma de decisiones ${ }^{12}$. Autonomía semántica no implica, naturalmente, ausencia de vaguedad. Por consiguiente habrá casos -los que caigan en la zona de penumbra-

${ }^{12}$ Sobre ello, vid. Schauer, 1991, cap. IX. 
en los que, con arreglo a las convenciones lingüísticas existentes, será dudoso si resulta o no aplicable una directiva que posee autonomía semántica. Pero esa clase de duda no tiene la misma naturaleza que aquella otra consistente en qué hacer cuando se presenta una experiencia recalcitrante, es decir, cuando se considera que en un caso en que la regla es claramente aplicable su cumplimiento no serviría a su justificación subyacente (o que en uno en el que claramente no es aplicable su justificación subyacente exigiría hacer también lo que la norma prescribe). Sólo el modelo puro basado en reglas excluye esta segunda fuente de casos difíciles. Fuera de él, sostener que un caso puede ser difícil aunque caiga dentro de la «zona de luz» de la norma tiene perfecto sentido. Pero ello no implica, como, por ejemplo, ha sostenido Guastini, que sean los órganos jurisdiccionales los que deciden si un caso cae en la zona de luz o en la de penumbra, ni que «la penumbra misma sea el resultado de la discrecionalidad de los intérpretes» (Guastini, 1992, 116): lo que los órganos jurisdiccionales deciden, me parece, no es eso, sino si tratan o no a una directiva como regla genuina.

Hechas estas precisiones, queda en pie una cuestión fundamental. ¿Cuál es entonces realmente -y también cuál debería ser- el papel de las reglas en el razonamiento jurídico, una vez que hemos aceptado que no es -ni debería ser- el que les atribuye el modelo puro basado en reglas? En el extremo contrario al modelo basado en reglas encontrarnos una imagen del razonamiento jurídico -a la que Schauer ha llamado «the jurisprudence of justification» (Schauer, 1987; 1991, 53, nota 1) y cuyo ejemplo más característico sería la propuesta de Dworkin- en la que las reglas son ilimitadamente moldeables a la luz de las justificaciones subyacentes al sistema en su conjunto. Frente a esta imagen, ¿no habría que reclamar que las reglas se tomen en serio? ¿no tienen acaso las reglas -y más aún, no deberían tener- una importancia en el razonamiento jurídico que se corre el riesgo de pasar por alto? Además, si a la imagen de unas reglas moldeables a la luz de las justificaciones subyacentes se le añade la sensata observación de que esas justificaciones no las encuentra uno dentro del sistema, sino que se proponen en relación con él, lo que resulta de todo ello es que, se quiera o no, se difuminan las fronteras que aíslan al razonamiento jurídico del razonamiento práctico general. Sin reglas que opongan alguna resistencia a la intervención directa de las justificaciones que se proponen respecto de ellas, la imagen del razonamiento jurídico como una esfera delimitada frente al discurso práctico general resulta insostenible. Parece, por tanto, que el rechazo del modelo puro basado en reglas compromete una cierta concepción no sólo acerca de la estructura del razonamiento práctico dentro de la esfera jurídica, sino también acerca de los límites de esa esfera.

El problema radica en que no parece fácil aclarar cuál es -y quizá también cuál debería ser- ese papel de las reglas si no es el que les atribuye el modelo puro basado en reglas. Creo que Atienza y Ruiz Manero intentan dar una respuesta a esta pregunta cuando sugieren que el derecho impone a 
los órganos jurisdiccionales el deber de componer un balance de razones que generalmente, pero no siempre, exige adoptar como base de su decisión una regla como razón perentoria (Atienza y Ruiz Manero, 1991, 118; 1992, 340-341). En los términos en los que está formulada, no obstante, la idea me resulta un tanto oscura. A mí me parece que la noción de razón perentoria simplemente no encaja con la afirmación de que un balance de razones decide si procede o no adoptarla. De hecho se supone que lo característico de una «razón perentoria» es que excluye esa clase de balance. Otra cosa distinta es que un balance de razones exija generalmente -pero no siempre- hacer lo que la regla prescribe. Pero en ese caso, tanto cuando exigen hacer lo que la regla prescribe como cuando exigen lo contrario, son aquellas razones, y no la regla, las que deciden el resultado.

Aun formulada en otros términos, me parece que la idea de Atienza y Ruiz Manero no es en el fondo muy distinta de la que propone Schauer bajo la etiqueta de positivismo presuntivo [presumptive positivism] o modelo presuntivo basado en reglas (Schauer, 1991, 196-206). Según Schauer, el modelo que mejor explica la práctica del razonamiento jurídico tal y como realmente se desarrolla -y a la vez el que le parece normativamente preferible- es uno según el cual las reglas gozan de «una prioridad fuerte pero superable [overridable]» (ibid., 204), lo que querría decir que la regla no deja de controlar la decisión cada vez que se entiende que lo que ella exige no es lo correcto a la luz de las justificaciones subyacentes, sino sólo cuando ese error (respecto a lo debido según dichas justificaciones) parece particularmente severo ${ }^{13}$.

Ahora bien, habría que preguntarse de dónde surge esa fuerza de las reglas y en qué punto -y por qué precisamente en él- deja de ser suficiente. Schauer no responde a estas preguntas, pero me parece que sólo hay una contestación posible: proviene de añadir a las razones subyacentes a las reglas las razones para tener esas reglas (actuando como razones añadidas para hacer lo que las reglas exigen) y llega tan lejos como lleguen éstas. Y en ese caso no existe diferencia extensional alguna entre el modelo presuntivo basado en reglas y lo que Schauer había llamado antes particularismo sensible a las reglas. Uno y otro, sencillamente acaban confundiéndose ${ }^{14}$.

Así que, después de todo, el particularismo sensible a las reglas puede ser el modelo que describe más adecuadamente cómo se desarrolla el razonamiento jurídico. Y me parece además el único racionalmente defendible (para aquel que acepte un conjunto de razones que puedan verosímilmente ser propuestas como justificación de un sistema normativo). Por todo ello,

${ }^{13}$ Eso es tanto como decir que hay una presunción (fuerte, pero vencible) en favor de la solución que dicta la regla; y de ahí la denominación peculiar -y que tan trabajosamente se deja trasladar a un castellano aceptable- que Schauer elige para este cuarto modelo.

15.

${ }^{14}$ Es la misma conclusión a la que llegan Postema, 1991, 813-817; y Alexander y Sherwin, 1994, 1198, nota 
no creo que una autoridad pueda pretender racionalmente que los destinatarios de sus reglas adopten frente a éstas una actitud distinta.

\section{BIBLIOGRAFÍA}

ALEXANDER, Larry, 1990: «Law and Exclusionary Reasons», Philosophical Topics, 18, 5-22. ALEXANDER, Larry y SHERWIN, Emily, 1994: «The Deceptive Nature of Rules», University of Pennsylvania Law Review, 142, 1191-1225.

ATIENZA, Manuel y RUIZ MANERO, Juan, 1991: «Sobre principios y reglas», Doxa, 10, 101-120.

-1992: «Objeciones de principio. Respuesta a Aleksander Peczenik y Luis Prieto Sanchis», Doxa, 12, 333-352.

BAYÓN, Juan Carlos, 1991a: La normatividad del derecho: deber jurídico y razones para la acción. Madrid: Centro de Estudios Constitucionales.

-1991b: «Razones y reglas: sobre el concepto de razón excluyente en Joseph Raz», Doxa, 10, 25-66.

CALABRESI, Guido, 1982: A Common Lawfor the Age of Statutes, Cambridge, Mass., Harvard University Press.

CLARKE, S.S., 1977: «Exclusionary Reasons», Mind, 86, 252-255.

DWORKIN, Ronald, 1986: Law's Empire, Cambridge, Mass., Harvard University Press.

EDMUNDSON, William A., 1993: «Rethinking Exclusionary Reasons: A Second Edition of Joseph Raz's Practical Reason and Norms», Law \& Philosophy, 12, 329-343.

FLATHMAN, Richard E., 1980: The Practice of Political Authority, Chicago, University of Chicago Press.

GANS, Chaim, 1981: The Concept of Duty, Oxford University (tesis doctoral inédita)

-1986: «Mandatory Rules and Exclusionary Reasons», Philosophia, 15, 373-394.

GUASTINI, Riccardo, 1992: Dalle fonti alle norme (2nd. ed.), Turin, Ghiappichelli.

HART, Herbert L.A., 1982: Essays on Bentham. Studies in Jurisprudence and Political Theory, Oxford, Clarendon Press.

HURD, Heidi M., 1991: «Challenging Authority», Yale Law Journal, 100, 1611-1677.

-1993: «Justifiably Punishing the Justified», Michigan Law Review, 90, 2203-2324.

LAGERSPETZ, Eerik, 1989: A Conventionalist Theory of Institutions, Helsinki, Acta Philosophica Fennica.

MACKIE, John L., 1977: Ethics: Inventing Right and Wrong, Harmondsworth, Penguin. 
MOORE, Michael S., 1989: «Authority, Law and Razian Reasons», Southern California Law Review, 62, 829-896.

NOWELL-SMITH, P. H., 1978: «On Legitimate Authority: A Reply to Joseph Raz», en R. Bronaugh (ed.) Philosphical Law: Authority, Equality, Adjudication, Privacy, Westport/Londres, Greenwood Press, 32-44.

PERRY, Stephen R., 1989: «Second-Order Reasons, Uncertainty and Legal Theory», Southern California Law Review, 62, 913-994.

POSTEMA, Gerald J., 1991: «Positivism, I Presume?... Comments on Schauer's «Rules and the 'Rule of Law'», Harvard Journal of Law and Public Policy, 14, 797-822.

RAZ, Joseph, 1975: Practical Reason and Norms, (1 ${ }^{\mathrm{a}}$ ed.), Londres, Hutchinson.

-1986: The Morality of Freedom, Oxford, Clarendon Press.

-1989: «Facing Up: A Reply», Southern California Law Review, 62, 1153-1235.

-1990: Practical Reason and Norms (2a ed., con el apéndice: «Rethinking Exclusionary Reasons»), Princeton N.J., Princeton University Press.

REGAN, Donald H., 1989: «Authority and Value: Reflections on Raz's Moraliry of Freedom», Southern California Law Review, 62, 995-1095.

SCHAUER, Frederick, 1987: «The Jurisprudence of Reasons» (reseña del libro de R. Dworkin Law's Empire), Michigan Law Review, 85, 847-870.

-1991: Playing by the Rules. A Philosophical Examination of Rule-Based Decision-Making in Law and in Life, Oxford, Clarendon Press.

SHINE, Roger A., 1992: «Exclusionary Reasons and the Explanation of Behaviour», Ratio Juris, $5,1-22$.

SIMON, Herbert A., 1957: Administrative Behavior, $2^{\text {a }}$ ed., New York, Macmillan (1 ${ }^{\mathrm{a}}$ ed.: 1945). 